\title{
Research and Exploration of Teaching in Electrical Controlling and PLC
}

\author{
$\mathrm{Li} \mathrm{Xiwu}^{1, \mathrm{a}}, \mathrm{Xu} \mathrm{Bo} \mathrm{B}^{2, \mathrm{~b}}$ \\ ${ }^{1}$ Engineering and Technology Academy of Jilin Agricultural University of China \\ ${ }^{2}$ Engineering and Technology Academy of Jilin Agricultural University of China \\ a xw1234@126.com, ${ }^{\text {b } x u b o b o a p p l e @ 163 . c o m ~}$
}

Keywords: electrical controlling; PLC; practice; teaching reforming

Abstract. "Electrical Controlling and Programmable Controller" is a more applied professional course in electrical engineering and automation. Exploration and summary are introduced for course teaching of "Electrical Controlling and Programmable Controller". Firstly, the teaching contents and outline adjusted, the methods of teaching and exam are improved. Secondly, reforming practice teaching, doing well laboratory construction, strengthening segment of experiment, reforming the segment of course design and practice, programming and simulation testing are introduced in this segment. Lastly this paper expounds the construction of teachers' team.

\section{Introduction}

In recent years, along with the deepening of educational reform, colleges and universities also have been adjustment of majors and courses reform.Electrical control and PLC is one of the main courses of Automation Specialty, and a wide coverage of knowledge, content, update fast, emphasis on theory and on Practice Course[1], Combined with practical production and engineering application, closely and widely application. This course in the teaching process, not only to cultivate students with theoretical knowledge, but also to the cultivation of students' practical ability, innovation ability.

\section{The reform of the course teaching}

\section{1 Adjustment syllabus, integration of teaching content}

Programmable logic controller (Programmable Conroller, PLC) is based on microprocessor as the core, highly integrated general industrial automatic control device, and is essential to the electrical control equipment. PLC integration of computer technology, automatic control technology and communication technology, its application covers almost all industrial enterprises, has become one of the three pillars of industrial automation. In the background of engineering quality education, innovation education is the core, for electrical control and PLC curriculum teaching reform is imperative [2]. In order to meet the need of automation of applied undergraduate talents training, integration of curriculum knowledge and the core technology, supporting technology, cross discipline is the key to the curriculum reform [3]. Based on the basic theory emphasizes the course, to reduce the traditional relay contact electrical control part of the course content, Prominent classic electrical control circuit relay contacts, links and typical design ideas, Emphasizes the principle of PLC ladder and analysis, design and application content, Increase the PLC control system of network technology, both in the control system of PC monitoring software design and development. The theory of teaching not only emphasizes the systematic, integrity theory, but also pay attention to the practical engineering application, and ensure that the proportion of class hour practice at the same time. Prominent experimental content and experimental requirements closely related to the theory of the teaching content can not only adapt to the actual production requirement, and can 
make the students' practical ability and innovation ability get exercise and improve.

\subsection{Improve teaching method, improve teaching effect comprehensively}

In the teaching of classroom, teachers insist on explaining in the way that writing on the blackboard predominates, making full of multimedia as teaching aid, with the use of body language teaching, so they not only grasp the rhythm of teaching, but also observe the reaction of students, in addition, give students time to think according to the actual situation, that is benefit of teaching effect. Teachers select suitable material by contrast, when teaching, appropriately increase some new contents on the basis of teaching material, and add the feeling of scientific research, technology development and engineering practice to the course content. In order to widen the field of vision, teachers should fill the content of a large number of low voltage components, common machine tool equipment, large and small PLC pictures of different manufactures and the structure, principle, principle diagram of electric control, ladder diagram and PLC network frame etc.

\subsection{Reform the inspection methods, promote the change in the style of study}

During the process of teaching, we implement course management, and make full assessment of the students, where the questioning in class, attendance, quizzes, tests, homework, the performance in class are combined as the usual results, which will be reckoned in the overall achievements in the proportion of $30 \%$.Besides, for the part of final exam, where the degree of the students understanding and acquiring the course is truly tested ,according to the syllabus and exam outline, and considering the distribution of the points of knowledge, the difficult of test, the proportion of all kinds of examination points, proposition etc, improving the coverage of test, strengthening the assessment of the typical circuit and typical application program of PLC have a good effect on promoting the enthusiasm of learning and the ability of comprehensive application.

\section{The reform exploration of practice teaching}

"Electrical Cont rolling and Programmable Controller" is a more applied and practical course, which can improve its theoretical level by the way of proving the validity of theoretical content through some practice. The teaching step of practice in the syllabus includes 3 parts, which are experiment, curriculum design and professional curriculum practice.

\subsection{Pay attention to experimental procedures link, improve the experimental level of students}

The laboratory is the first place for students' practice, the basis of the construction and development of course, the material basis of training application-oriented engineering talents. Laboratory equipment and management level, are the key factor to develop the ability of students' practice.

PLC laboratory is built in 2005 by Jilin Agriculture University, which has acquired 25 sets of PLC experimental device, equipped Siemens CPU224 24 points I/O host and related experimental module, the PLC of multiple OMRON C200H medium module type, the process controlling test bench taking Siemens CPU224 as the core above 2,commonly used industrial controlling module including the configuration software, touch screen, frequency converter etc,8 electrical cabinets which can make achieve PLC and inverter achieve communicating controlling. PLC lab opens 2 parts of experimental contents including relay controlling and PLC. Relay controlling opens common controlling elements and motor controlling experiment; PLC opens "liquid mixed analog controlling”, "five layers elevator simulation controlling”, "production line simulation controlling", “traffic signal controlling of crossroad”, “motor $\mathrm{Y}-\triangle$ controlling” and so on.

Experimental teachers are served as the course instructor, who are responsible for explaining, 
guidance, and counseling to the student' experiment. In the process of the experiment, teachers will be able to put stress and difficulty in the theory teaching through the experimental content and layout, that plays a complementary and intensive role in helping students master the knowledge point, avoiding disconnection between teaching and experiment. Before each experiment, teachers should assigned subjects to students one week ahead, and explain the knowledge point involved the experiment, requiring students to preview before, to write the preview report, to put forward specific requirement for the report, such as drawing the main circuit and controlling circuit, writing all the necessary procedures above the experiments. The nature of the experiment is divided into 3 including verification, design and synthesis, the arrangement of content is from the shallower to the deeper, making the point stand out. In the course of experiment, making full use of students' initiative and subjectivity, and making students determine the experiment scheme, draw the circuit connection diagram and programming according to experimental contents, attach and debug on the test rig, until the realization of the experimental goal, it is better to train the students' ability of thinking, design and practice. Teachers play a supporting and guiding role in the whole process, checking students' experiment and troubleshooting problems they encounter.

In order to ensure the quality of student experiment, teachers need to combine the experimental results of every group to verify, questioning randomly about knowledge points of experiment and the possible phenomenon, students must analyze briefly and answer based on the theory and the experimental results, so teachers will result this experiment according to their answer. This ensures that teachers can open a high quality experiment class within the finite time.

Usually, teachers and PLC lab manager open up the second classroom for the students, and students can book open laboratory to create conditions for theoretical study, exploratory attempt, and cultivating engineering ability. Making full use of the ability of students' self-study, and training part of students who have the ample force, interest and talent, these excellent students will be seen after that. In addition, those students who have spare capacity to learn and interest can be arranged to participate in the teachers' scientific research, to exercise the ability of theory with practice, learning new knowledge and engineering practice.

\subsection{Strengthen curriculum designed to improve students' ability to design}

Curriculum design is an important teaching link of Automation, has the function of teaching gradually deepened. Under the guidance of teachers, students independently complete a design, through the process to implement the training of the students' comprehensive design ability.

Under the condition of school facilities can realize select a topic of curriculum design as far as possible from the actual production. Select a topic in ensuring the premise of having the practicality and usefulness, and consider the advanced nature of its contents. Such topic can be simulated debugging through laboratory furniture, improved operability.

Stressed the dominant position of students in the design, focusing on engineering practice ability, analytical ability to solve practical problems of training and strict style of work, in addition to requires students to design the control program, but also requires students to use the equipment of laboratory experiments PLC for simulation debugging. For the programming problems can be find by simulated debugging in a timely manner, through their own search and resolved under the guidance of teachers, to better achieve the connection between theory and practice and identify problems, thinking, problem-solving purposes, was welcomed by many students, generally feel a greater harvest, the curriculum design student participation, motivation is generally high. 


\subsection{Professional integrated curriculum design and graduate design combine to improve students' ability to apply comprehensive knowledge}

As a result of automation, the characteristics of strong practicality in the eighth semester arranged the comprehensive curriculum design. The design of professional curriculum is to investigate students' mastery of the knowledge of automation level, as well as comprehensive knowledge and ability to use automated processes and important means [4]. There are 10 sets of laboratory designed and installed large electrical control cabinet, cabinet equipped with inverter, starters , PLC, contactors, relays and components such as buttons, able to drag two single AC induction motor work to achieve variety of control sta rting, running, stopping and speed and so on. When designing, the two students use an electrical control cabinet, according to the arrangement of the control cabinet components, component layout draw record specifications, models and number, etc. look for common low-voltage electrical manuals and textbooks and other information are familiar with these devices, and using the multimeter as an auxiliary tool to detect, draw electrical control circuit. Drawn on the basis of the PLC I / O wiring diagram and the input and output allocation table, write the ladder program, then enter the PLC lab, using a computer, PLC host and switch button lights to simulate debug and modify, debug functions to achieve conformity after running the experiment on the actual electrical control cabinet.

\section{Focus on the construction of dual-qualified teachers}

This course requires teachers besides has high theoretical level, must also have some ability in engineering and scientific research and development ability [5]. In addition to the completion of the work of teachers teaching the theory, but also actively participate in the construction of laboratories and research work. Teachers engaged in engineering and research and development, not only exercise the teachers, teachers of theoretical knowledge and practical ability has improved, which in turn will further enrich the teaching content and promote the improvement of the standard of teaching. Teachers also combine with engineering practice or production plans, and put configuration software, touch screen, inverter and other aspects practical knowledge into students' graduation design to improve the students' ability in engineering applications.

\section{Conclusions}

After several years of efforts, we have made some exploration and research on "Electrical Controlling and Programmable Controller" course teaching reform and practice, has achieved some success. We need to continue to move forward in the future teaching, efforts to cultivate conform to the social demand and train professional qualified automation of college graduates.

\section{References}

[1] Wan Qiulan. Electrical Engineering in the 21st Century Personnel Training Mode and Teaching Content and Course System Reform [J]. Electrical \& Electronic Education, 1999, 21 (4)

[2]Shu Changbao, Li Xinbing, Wang Yonghua, et al. Exploration of Teaching Reforms in Electrical Controlling and Programmable Controller [J]. Journal of EEE, 2005, 27 (6).

[3] Xia Jianguo. Positioning Technology Applied Undergraduate Education Institutions Thinking. [J]. Higher Engineering Education Research, 2006, (6)

[4] Xiong Xingming, He Xinjun, Zhang Zhigang. The Refrom and Explorations on the Course Design of Controlling Technology on Factory Electricity [J]. Journal of EEE, 2004, 26 (3)

[5] Huang Jian, Song Lirong. Investigate the automatic control of the class curriculum experimental teaching reform [J]. Experimental Technology and Management, 2005 (3) 